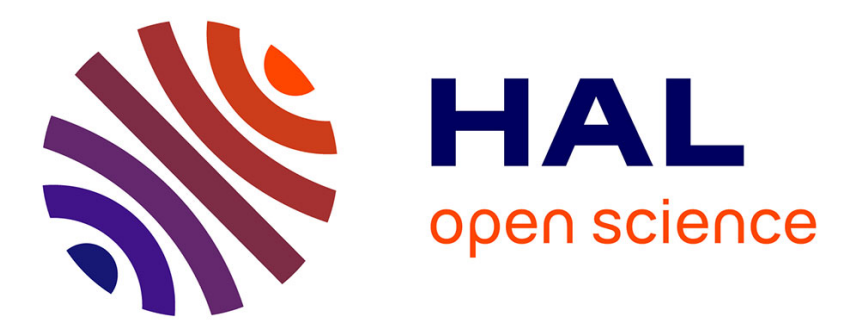

\title{
In-situ study of high temperature corrosion kinetics of iron using a fast $\mathrm{X}$-ray diffraction method
}

\author{
M. Juez-Lorenzo, V. Kolarik, N. Eisenreich, W. Engel, A. Criado
}

\section{To cite this version:}

M. Juez-Lorenzo, V. Kolarik, N. Eisenreich, W. Engel, A. Criado. In-situ study of high temperature corrosion kinetics of iron using a fast X-ray diffraction method. Journal de Physique IV Proceedings, 1993, 03 (C9), pp.C9-461-C9-467. 10.1051/jp4:1993949 . jpa-00252389

\section{HAL Id: jpa-00252389 https://hal.science/jpa-00252389}

Submitted on 1 Jan 1993

HAL is a multi-disciplinary open access archive for the deposit and dissemination of scientific research documents, whether they are published or not. The documents may come from teaching and research institutions in France or abroad, or from public or private research centers.
L'archive ouverte pluridisciplinaire HAL, est destinée au dépôt et à la diffusion de documents scientifiques de niveau recherche, publiés ou non, émanant des établissements d'enseignement et de recherche français ou étrangers, des laboratoires publics ou privés. 


\title{
In-situ study of high temperature corrosion kinetics of iron using a fast X-ray diffraction method
}

\author{
M. Juez-Lorenzo( $\left(^{1}\right)$, V. Kolarik $\left({ }^{1}\right)$, N. Eisenreich $\left({ }^{1}\right)$, W. Engel $\left({ }^{1}\right)$ and A.J. Criado $\left({ }^{2}\right)$
}

(1) Fraunhofer-Institut für Chemische Technologie ICT, Joseph-von-Fraunhofer Straße, 7507 Pfinztal 1, Germany

$\left.{ }^{2}\right)$ Departamento de Ciencia de los Materiales e Ingeniería Metalúrgica, Fac. Químicas, Universidad Complutense de Madrid, Spain

\begin{abstract}
Temperature and time resolved X-ray diffraction was applied to studies of the high temperature oxidation of iron in air in isothermal measurements between 700 and $920^{\circ} \mathrm{C}$. With the measured series of diffraction patterns the formation of the oxide layers can be followed in situ. The observed diffraction peaks allow the identification of the oxides. The difference method together with microscopic determination of the end thickness of the oxide layer yields the kinetic parameters for the whole oxide layer as well as for the single oxides.
\end{abstract}

\section{Introduction.}

Corrosion at high temperatures is a serious problem in many applications. The development of high temperature resistant alloys requires detailed knowledge of all corrosion phenomena [1, 2]. The methods applied to the investigation of high temperature corrosion usually don't allow in situ studies. The samples are oxidized under defined conditions in ovens and studied after cooling [3]. In many cases phase transitions, solid state reactions and stresses leading to a flaking of the oxide layer may occur on heating and cooling. Therefore the in situ identification of the oxidation products is required. An investigation on thin iron films was reported taking into account only the $(110)_{\text {Fe }}$ peak [4]. The studies of oxidation kinetics, however, should be performed with more oxide peaks to avoid confusion of texture effects with oxidation kinetics. Thermogravimetry (TG), one of the mostly used in situ methods, shows only weight changes, but does not identify the present phases.

A measuring system was built up that allows the required in situ investigation of the corrosion processes using X-ray diffraction $[5,6]$. Series of diffraction diagrams are recorded with fast detectors during a freely selectable temperature program showing the structural and chemical changes of the sample. The new experimental possibilities are demonstrated with investigations of the high temperature oxidation of pure iron.

\section{Experimental.}

2.1 MEASURING SYSTEM. - The measuring system consists of an X-ray diffractometer combined with a high temperature device. Angle dispersive or energy dispersive measurements can be performed. The angle dispersive measurements are recorded with a position sensitive proportional counter, which permits a fast scanning of the measuring sector yielding 
short measuring times (100 to $120 \mathrm{~s}$ ), or with a scintillation counter. The energy dispersive measurements are performed with the continuous spectrum of a tungsten tube at a constant diffractometer angle of $2 \theta=20^{\circ}$ using a $\mathrm{Si}(\mathrm{Li})$-detector. The method permits measuring times of 60 to $120 \mathrm{~s}$ per diffraction spectrum. The sample temperature can be varied stepwise or continuously between 20 and $1700^{\circ} \mathrm{C}$ controlled by a freely selectable temperature program. on each temperature step or after defined time intervals a diffraction pattern is recorded. Series of 300 diffraction patterns can be measured during one day.

2.2 Measurements. - Fe-ARMCO (impurities contents: $0.004 \% \mathrm{C}, 0.03 \% \mathrm{Mn}, 0.001 \% \mathrm{Si}$, $0.004 \% \mathrm{P}$ and $0.007 \% \mathrm{~S}$ ) was oxidized in air at 700,800 and $920^{\circ} \mathrm{C}$. The relative moisture of the air in the laboratory was $30 \%$ at a temperature of $24^{\circ} \mathrm{C}$.

\section{Evaluation.}

3.1 DifFERENCE METHOD. - Evaluating the diffraction patterns a Gauss curve was fitted to the measured peaks, as it leads to sufficiently precise results. The lattice plane distances $d(h k l)$ and the intensities of the diffraction peaks were plotted against temperature.

Global changes in the diffraction patterns were determined by means of the difference method as described extensively elsewhere [5]. Two diffraction patterns or sections of them are subtracted. The sum of the absolute values $Y(T)$ correlates with the changes in the diffraction patterns.

$$
Y(T)=\sum_{i=1}^{n}\left|Y_{i}\left(T_{1}\right)-Y_{i}\left(T_{j}\right)\right|
$$

with $j=$ number of the current patterns; $i=$ number of the current channel; $n=$ total number of channels.

For the determination of the kinetics the difference sums $Y(T)$ were constantly formed with the first pattern.

3.2 ISOTHERMAL KINETICS. - The $Y(t)$ curves showing the relative changes in the surface layer are normalized to 1 . The $Y\left(t_{j}\right)$ values are then multiplied by the final thickness of the oxide layer that was measured microscopically. The obtained curve $x(t)$ is supposed to represent the time dependence of the growth of the oxide layer [6]. Theoretical parabolic curves were fitted to the measured $x(t)$ curves yielding the oxidation rate constants.

The application of the difference method to selected sections of the diffraction patterns yields separate $Y(t)$ curves for each oxide:

$$
Y(t)_{\text {total }}=Y(t)_{\mathrm{Fe}}+Y(t)_{\mathrm{FeO}}+Y(t)_{\mathrm{Fe}_{2} \mathrm{O}_{3}}+Y(t)_{\mathrm{Fe}_{3} \mathrm{O}_{4}}+Y(t)_{\mathrm{background}}
$$

In this way kinetic parameters for the formation of each oxide layer can be determined in only one experiment. 


\section{Results and discussion.}

The isothermal oxidation of Fe-ARMCO was studied with two methods: Energy dispersive and angle dispersive X-ray diffraction.

Comparing energy and angle dispersive measurements it turns out that angle dispersive measurements are distinguished with a better resolution (Figs. 1, 2). However, they suffer from a low penetration, when the layers surpass a certain thickness. The harder X-rays used in energy dispersive measurements provide sufficient penetration, even when the layers surpass a thickness of $200 \mu \mathrm{m}$, but the measurements suffer from a poorer resolution.

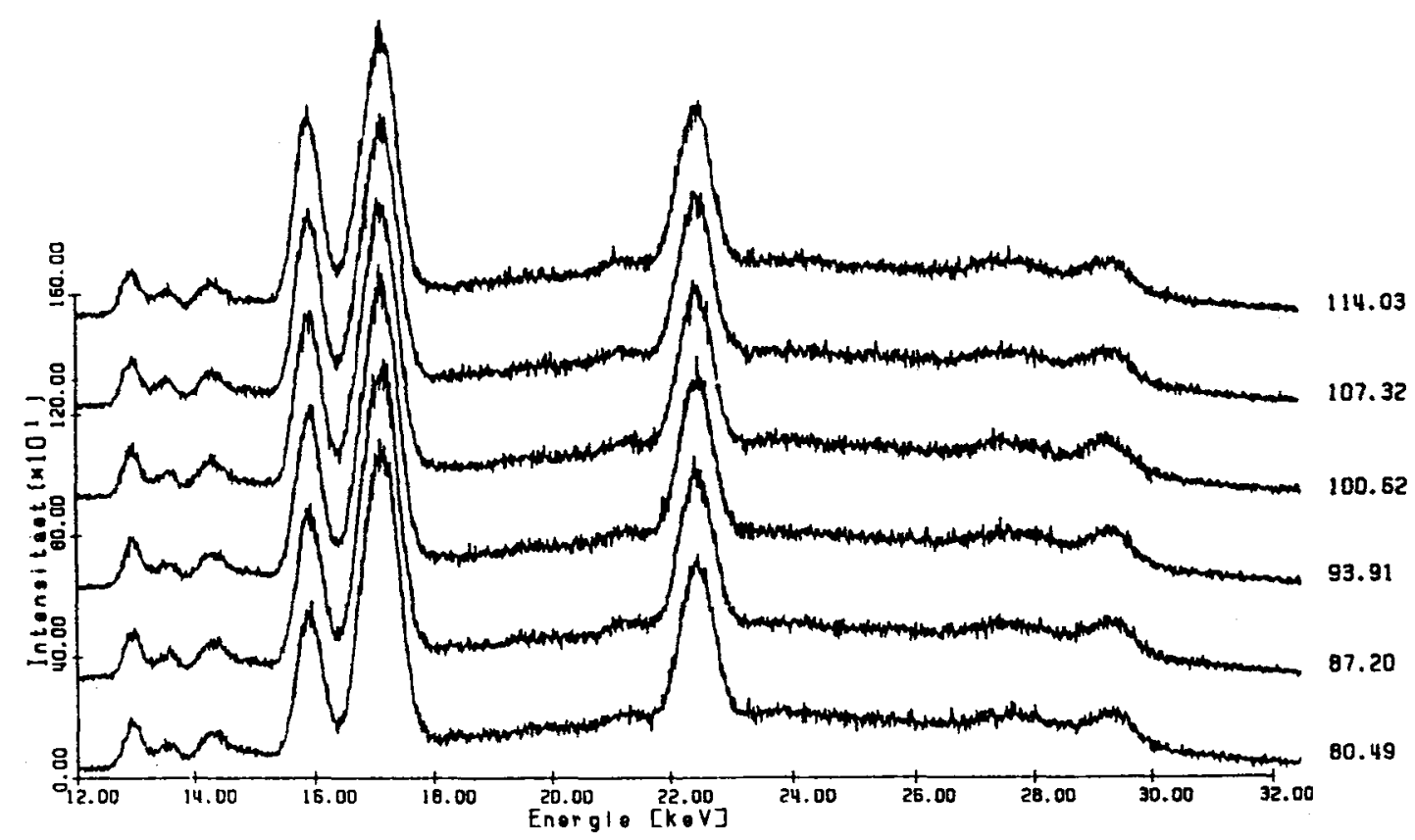

Fig. 1. - Energy dispersive series of diffraction patterns.

For the determination of the kinetic parameters differences curves were formed and calibrated as described in 3.1 for the whole spectra of a series measured at $800^{\circ} \mathrm{C}$. Besides, difference curves were formed with separate regions containing uniquely the peaks of the different oxide species (Fig. 3). After the microscopic measurement of the end thickness and calibration of the corresponding difference curves the parabolic constants for the whole layer as well as for the separate oxide layers could be determined (Tab. I). The evaluation procedure is very sensitive to curvature of the $x(t)$-curve, but less sensitive to errors in the measured end thickness. The measured growth of the single oxide layers $x(t)$ and the fitted curves are shown in figure 4. 


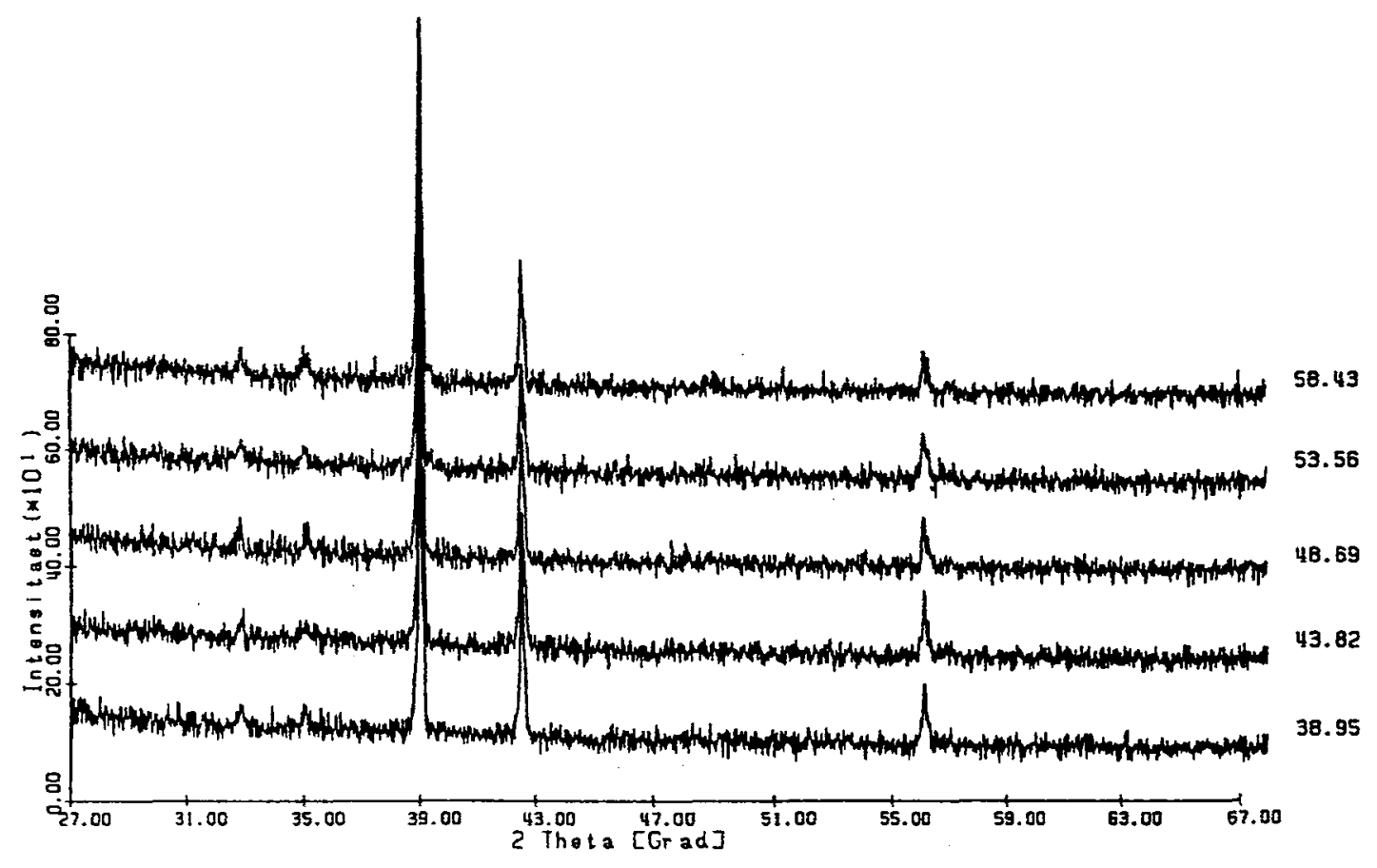

Fig. 2. - Angle dispersive series of diffraction patterns.

Table I. - Parabolic rate constants of the single iron oxides at $800^{\circ} \mathrm{C}$.

\begin{tabular}{|c|c|c|c|c|}
\hline & Total & $\mathrm{FeO}$ & $\mathrm{Fe}_{3} \mathrm{O}_{4}$ & $\mathrm{Fe}_{2} \mathrm{O}_{3}$ \\
\hline $\begin{array}{c}\text { Parabolic constant } \\
k\left[\mathrm{~g}^{2} \mathrm{~cm}^{-4} \mathrm{~s}^{-1}\right]\end{array}$ & $0.24 \times 10^{-7}$ & $0.22 \times 10^{-7}$ & $0.63 \times 10^{-10}$ & $0.36 \times 10^{-13}$ \\
\hline
\end{tabular}

The determination of the constants for the separate oxide species is difficult, because some of the broad energy dispersive peaks overlap (Fig. 1). Therefore angle dispersive series were measured. The narrower peaks of the angle dispersive measurements (Fig. 2) facilitate the separation of the peaks of the different species. The difference curves are comparable. Figure 5 shows difference curves calculated with magnetite peaks from energy and angle dispersive measurements. A kinetic evaluation is possible because the penetration of the X-ray in the two cases is high enough to penetrate this layer. The accuracy of the peak isolation in the angle dispersive method is much higher. Therefore the kinetic curve obtained from the angle dispersive X-ray diffraction method is more relevant. Further experiments will be carried out.

The wustite and hematite can also be identified in both cases, but in the energy dispersive case the identification of the peaks is difficult because the peaks are wide. The lattice plane distances obtained by means of angle dispersive measurements yield more accurate values. 


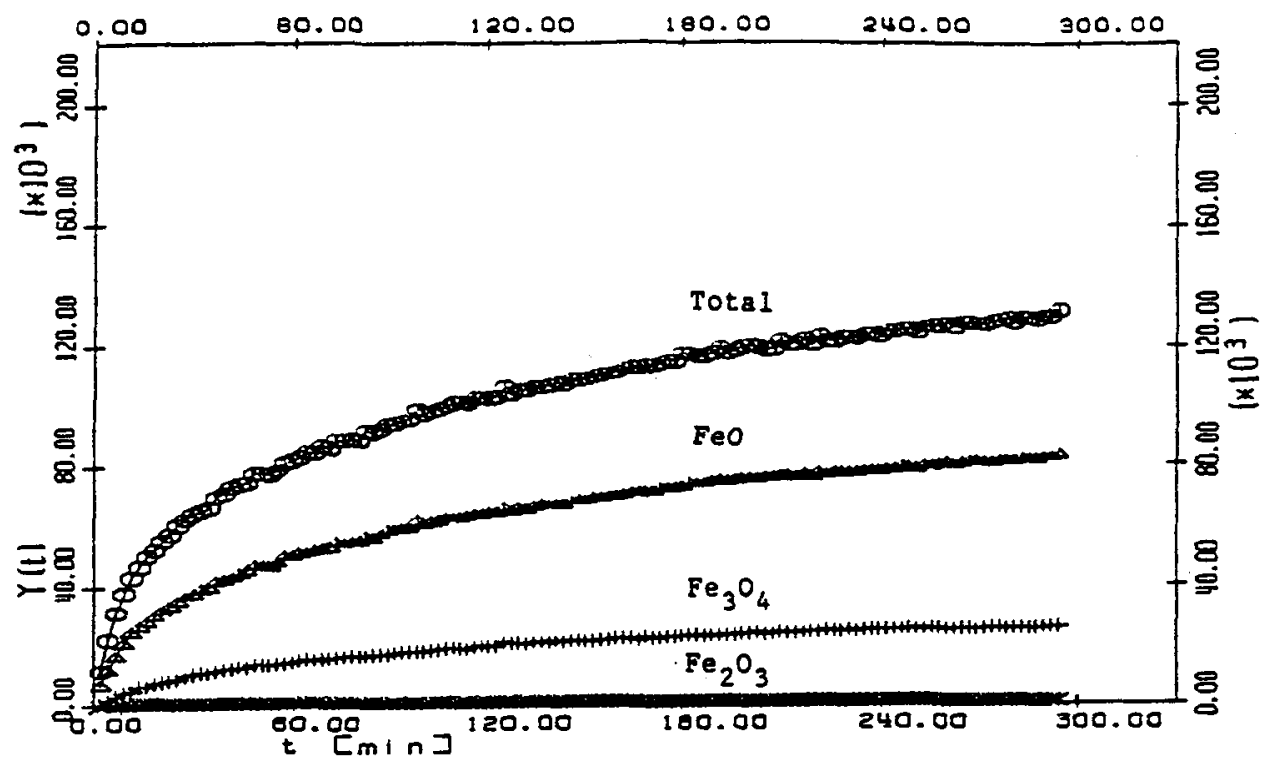

Fig. 3. - Difference curves $Y(T)$ of the isothermal experiment at $800^{\circ} \mathrm{C}$. The difference method was applied to each oxide separatelly.

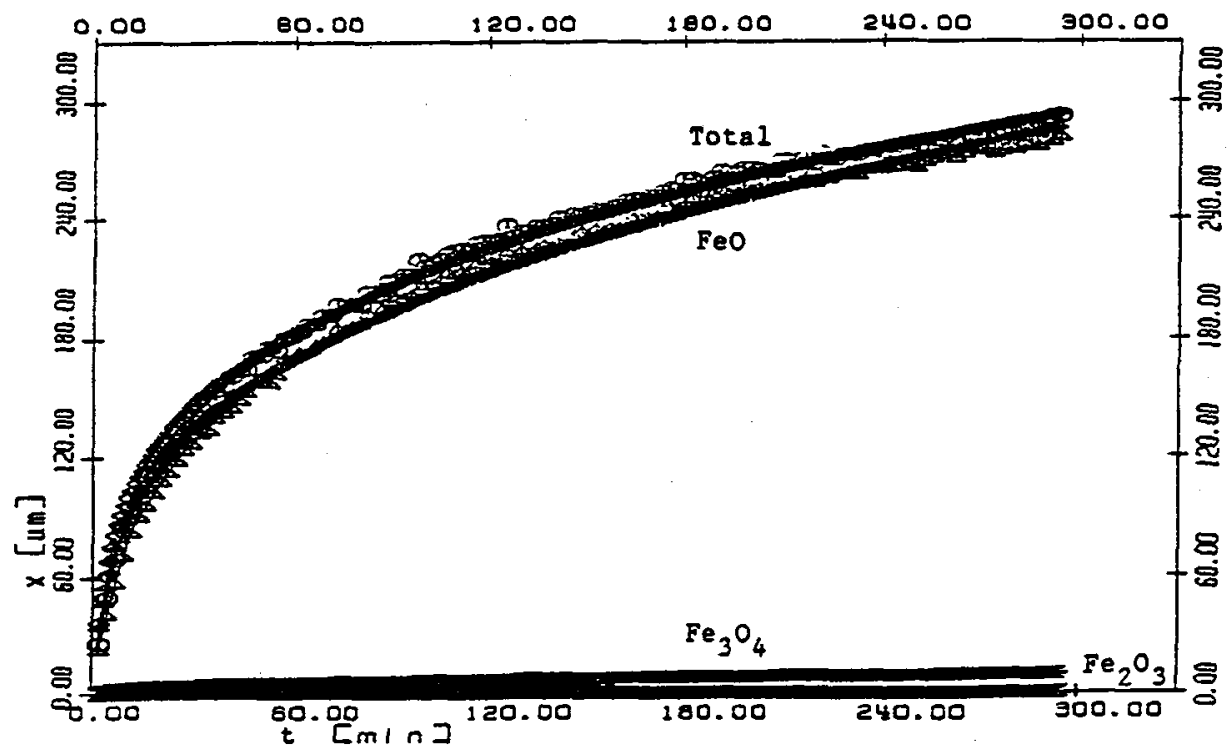

Fig. 4. - Growth of the different oxide layers $x(t)$ with the fitted curves. 
$\Delta$ Angle dispersive X-ray diffraction

(- Energy dispersive $X$-ray diffraction

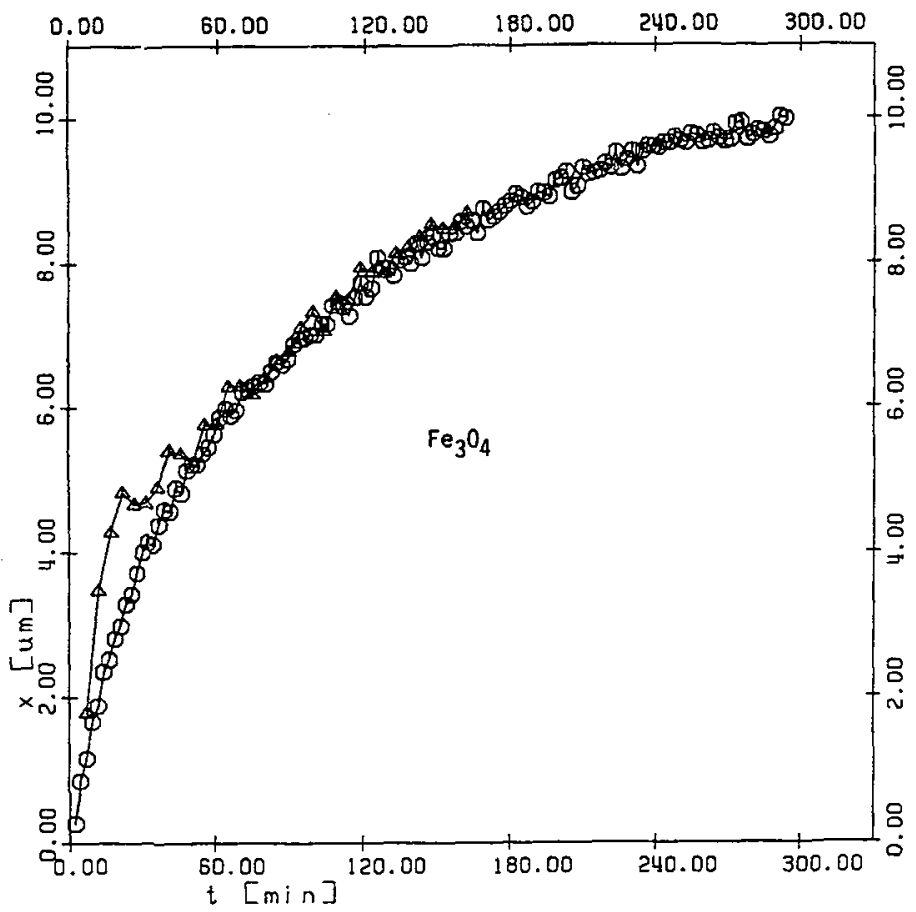

Fig. 5. - Comparison of the difference diagrams of $\mathrm{Fe}_{3} \mathrm{O}_{4}$ obtained by energy and angle dispersive $\mathrm{X}$-ray diffraction.

\section{Conclusions.}

$\mathrm{X}$-ray diffraction is a suitable method for the investigation of high temperature corrosion and its kinetics. The formed phases can be identified in situ and the temperature and time dependence of the oxidation rate constant for the whole layer as well as for the single oxide scales can be determined by means of the difference method.

\section{References}

[1] Rahmel A., Schwenk W., Korrosion und Korrosionsschutz von Stählen (Verlag Chemie, 1977).

[2] KOFSTAD P., High Temperature Corrosion (Elsevier Applied Science LTD, 1988). 
[3] Otero E., Criado A.J., Hierro P., Pardo A., Baladia M., Corrosion Behaviour of a Stainless steel 12Cr 1Mo 0.3V 0.2C at temperatures higher than $973 \mathrm{~K}$., Proc. 22nd Int. Annual Conf. of ICT, Combustion and Reaction Kinetics, 114(1)/ 114(7) (1991).

[4] WißSmann P., Zitzmann H., Anal. Chem. 319 (1984) 591-594.

[5] EISENREICH N., ENGEL W., J. Appl. Cryst. 16 (1983) 259-263.

[6] Kolarik V., JUEZ LORENZO M., EISENREICH N., ENGEL W., High-Temperature Corrosion Kinetics Using a Fast X-Ray Diffraction Method, First European Power Diffraction Conference EPDIC 1, Poster p 10.10 (München, 1991). 